\title{
Exploring Art Therapy as a Treatment for Children with Autism Spectrum Disorder
}

\author{
Junhyeong Jeong ${ }^{1}$ and Paul Shim ${ }^{\#}$ \\ ${ }^{1}$ Lynbrook High School, San Jose, CA USA \\ \#Advisor
}

\section{$\underline{\text { ABSTRACT }}$}

The purpose of this study is to understand the various therapies for children with autism spectrum disorder (ASD) and to discover a more effective method in connection with the research results in other fields. Art therapy was initially used at British mental hospitals to help frequently inhibited patients release creative and positive energy. As art therapy gained more attention, its usage expanded to help cure patients not only with mental disorders, but also developmental disorders like ASD. Actively used in social facilities and psychiatric treatment, art therapy is one of the most used methods to interact and understand individuals with ASD. Substantial number of papers have been published based on these various practical case studies, which proves the effectiveness of art therapy. Art therapy for children with ASD includes the following: clay, corrugated cardboard work and color mix work, drawing with crayon, paint, and pastel. These materials are frequently used to draw or create body parts, emotions, motions, and specific objects given by the instructor. From the data from research papers, clay and other tactile materials are one of the most effective materials to use to improve the condition of individuals with ASD, major depressive disorder, anxiety, and other mental disorders. Clay-based methods use the sense of touch and vision to create an abstraction process. As the usage of art therapy continues to increase in various fields, integrating effective methods among other disorders is necessary and further investigation is needed for a more effective therapy method for individuals with ASD.

\section{Introduction}

\section{Background}

Autism Spectrum Disorder is a developmental disability that can cause significant social, communication and behavioral challenges. People with autism possess difficulties in areas of verbal and nonverbal communication, social and relational skills, theory of mind, rigid and perseverative behaviors, and sensory integration dysfunction (Centers for Disease Control and Prevention). Children with ASD lack social skills, which differentiates them from their typical peers and classmates. When children with ASD go to elementary school, they might have important relational problems such as difficulties initiating and maintaining friendships with others (D'Amico, M. \& Lalonde, C., 2017). Autism also presents sensory challenges that are pervasive throughout the spectrum and affect different individuals to different degrees and domains. ASD might affect senses, such as the senses of smell (olfactory), movement (kinesthetic), sense of equilibrium (vestibular), awareness of body in space (proprioception), touch (tactile), sight (visual), and hearing (auditory) (Durrani H., 2020).

My first interaction with children with autism spectrum disorder was when I started volunteering at the local shelter for special needs children. After going through trial and error, I was able to build relationships with the children and get to know them better. One child, who is 13 years old, communicates with me the most. He possesses common signs of autism spectrum disorder, such as frequently leaving the conversation by walking away or not looking at the way I'm pointing. However, he answers my questions, knows how to write his name, and is cooperative in activities. 
For each of my visits, the art project is planned for the children by myself. For example, in April, since Easter was right around the corner, I had the children decorate eggs with paint and color pens. Since arts and crafts are seen as a very important part of the program, I wondered what effect arts and crafts have on the children with special needs. As I researched about the effects of art therapy on individuals with autism spectrum disorder, I have noticed that there are many types of art therapy: drawing, building blocks, crafting with clay and crackers, and more. Looking at each of the art therapy programs introduced in the research papers, I have noticed that clay is a material that is used frequently. ASD is not the only field where art therapy is used; it is also used to cure patients suffering from diseases including major depressive disorder, anxiety disorder, and trauma. Recently therapy usage has increased as a higher percentage of the population suffers from mental disorders. In order to develop an updated therapy program for the individuals with special needs, combining effective methods from other therapies is inevitable. By analyzing the effectiveness of the previous studies done with different types of art therapy and finding a common ground of the effective methods, it is the goal of this study to understand the various therapies for children with autism spectrum disorder (ASD), research for previous art therapy studies in other fields and their results, and explore the possibilities of art therapy method for the individuals with special needs.

\section{Methods}

In order to find the appropriate existing research papers, I primarily used Google Scholar, PubMed, and Naver Academic search engines, along with the research papers referenced in the papers. Then I chose articles that effectively display the effects of art therapy through specific methods and tests. Description of the testing method and interpretation of the data were heavily considered when evaluating articles, especially to prove the impacts art therapy can have on individuals and later focus on one of the methods of art therapy-clay therapy. This review did not focus on the long-term effects of art therapy, but rather studies in which art therapy showed effect in behavioral development and analyzed possible elements of clay therapy that can be beneficial to individuals with autism spectrum disorder.

\section{Literature Review}

\section{Efficacy and Limitation of Art Therapy}

Art therapy is considered as one of the most effective therapy because of its unique characteristics. Therapists have found that brief art therapy programs avail patients to open up about their feelings and thus expedite the assessment and intervention. Even if the program itself only involves simple tasks, they could lead to numerous expressions that cannot result from conversations with words. (Malchiodi, C. A., 2012) This can be accounted for by the brain activity that is activated by art programs that require creativity and imagination. Ramachandran (1999), and others have demonstrated that both hemispheres of the brain are necessary for art expression, which is proven by the drawings of people with damage to specific areas of the brain (Malchiodi, C. A., 2012). Previous researchers have discovered that language and certain movements in drawing are related. Utilizing the positron emission tomography (PET) scan, researchers recorded the brain activity of individuals drawing forms in space. The results show that even simple drawing, like many art therapy programs use, involves complex interactions between many parts of the brain (Frith $\&$ Law, 1995). Art therapy allows the patients to activate their brain and express their hidden emotions that they cannot express with simple words during conversation. One reason why art therapy is getting the spotlight nowadays is because of its efficiency. Art therapy can result in a notable improvement with a brief session with the patient due to brain activity that occurs while engaging in art programs.

Another positive effect of art therapy is that it also helps cure other illnesses that individuals with ASD might carry. Medical conditions associated with autism spectrum disorder include anxiety, depression, bipolar disorder, and 
schizophrenia. Art therapy is specifically effective in treating mental disorders because of the effect that images have on human's emotions.

Art therapy is deemed effective to people with various diseases because of its use of images. Images affect the patients' emotions, thoughts, and well-being. The way brain and body react to art explains the reason behind art therapy's effectiveness. "Mind-body medicine" is a popular term used to describe this approach that claims that the mind has a central impact on the body's health. (Malchiodi, C. A., 2012) Therefore, when art therapy is used as a treatment for people with depression, artwork and active imagination experiences eventually reflects a slow transformation from depression to more positive feelings about the future. Art helps patients overcome their depression, find a release from their illness, and discover a sense of well-being.

Despite its benefits, art therapy also has limitations. For example, art therapist Anita Rankin (1994) conducted a psychological study about tree drawings and the validity of trauma indicators that are seen in the drawings. Despite being able to find signs of previous injuries that led to the patient's trauma, Rankin was unable to find evidence that supports the conventional interpretation that existence of knotholes on the tree determines a traumatic behavior. She also failed to find a plausible reason behind the belief that the position of the knothole signifies the date of the traumatic event. (Malchiodi, C. A., 2012)

Despite the large volume of negative evidence, the DAP(Draw-A-Person), HTP(House-Tree-Person), and similar projective drawing techniques have remained popular with therapists (Groth Marnat, 1997; Motta et al., 1993). While self-diagnostic tests are widely used to determine the effects of art therapy on children with autism spectrum disorder, tests that require critical thinking skills like HTP and SCT (Sentence Complete Test) are also popular. In The Effects of Art Therapy on Self Expression of Adolescents with Autistic Disorder (Lim, J. H. et al., 2015), researchers divided the program into three large stages. The initial (1 4th) stage was 'rapport formation and emotional relaxation', the middle (5 19) stage was 'emotional exploration and expression', and the final stage (20 25) was 'selfacceptance stage'. The therapy program involved drawing, clay, chips/crackers, and more. After each session, the therapist always had a conversation about the topic with the child. They met with the child 25 times, an hour per session. Due to the usage of the HTP test, the researchers were able to analyze the results in a different way. Before the child drew trees over the house (fantasy, imagination) and had a few windows (passive interpersonal relationship). However, he drew a house without trees above (decreased imagination) and more windows with birds and fish near the house (longing for openness and environmental contact and developed an active interpersonal relationship). By using the HTP test, the researchers discovered the child's improvement without having to deeply communicate with words, which might have been difficult for the child. Furthermore, the researchers had set up stages, which allowed the child's conditions to become progressively better.

Since art therapy is proven to be effective for depression and anxiety, which are common medical conditions associated with autism, art therapy is also effective for autism spectrum disorder. Even though autism spectrum disorder currently cannot be cured, art therapy allows the therapists to effectively communicate with patients.

Art therapy could be viewed as one-on-one sessions between a therapist and a patient, but it could also be between a therapist and a group. In the study Effect of the Family-based Art Therapy Program on the Social Interactions, Verbal Skills and Stereotypic Behaviors of Children with Autism Spectrum Disorders (ASD) (Moghaddam K et al., 2016), researchers studied the benefits of including family members in the program for the family's better understanding of autism spectrum disorder. Researchers also expected a better result of social interactions, verbal skills and stereotypic behaviors of the child due to the family members, who the patient is familiar with, involved in the program. The therapy program consisted of painting, clay, and music. The family met with the therapist 15 times in person and 15 times at home. Using the Gilliam Autism Rating Scale and Bonferroni follow up test and covariance, the researchers calculated the effectiveness of the program. The obtained eta squared value was 0.24 , so the hypothesis was approved. Therefore, the researchers concluded that family-based art therapy has a significant effect on signs of autism.

Drawing and crafting objects are the most popular artwork used in art therapy for individuals with ASD. However, researchers have also conducted a study that shows making human faces and emotions also benefits the patients. In A Case Study on the Effect of Art Therapy Improvement of the Sociality of an Autistic Child (Ka-Young 
Oh., 2011), a therapist met with a 6-year-old child that has severe developmental disorder. The child could not interact well, did not look at others, and did not listen to the instructor, which are all signs of autism spectrum disorder. A therapist and the child met 12 times in total. Starting with free draws, the program increased the complexity of the artwork, ending with drawing the child's own face and making a cake. In result, the scores of all subdomains of the social functioning and behavior evaluation of children with autism (social responsibility, self-assertion, prosocial body posture, and overall score) were improved.

Activities using one's own body, such as hand printing, drawing various expressions, drawing one's face, and drawing oneself, help children recognize themselves. It was found that the social behavior was improved, shown in the child's actions of imitating, asking the therapist, receiving and using the object that the therapist handed to them. These results showed that sociality was improved by providing an opportunity to increase interaction with others by exploring and recognizing the body

\section{Clay Therapy for Common Mental Disorders}

Although clay is often neglected when discussing methods of art therapy, clay's unique properties offer two therapeutic purposes. First, clay's tactile sensations and malleability lets the therapists check the patients' emotional expression without having a verbal conversation. Furthermore, clay modeling activates the patients' creative impulses by letting them craft a formless mass to concrete and meaningful object discussions (Elizabeth R. Kimport \& Steven J. Robbins, 2012).

In Efficacy of Creative Clay Work for Reducing Negative Mood: A Randomized Controlled Trial (Kimport, E. R., \& Robbins, S. J., 2012), researchers designed a study in order to check if clay work could be the sole cause of mood enhancement of the subjects and emphasize the importance of having a structured task with a specific goal when using the creative nature of clay. In this study, in order to compare mood changes depending on the object they use for therapy, 102 adult participants were divided into 4 groups. Using the $2 \times 2 \times 3$ factorial design, the researchers used objects (clay or stress ball) as the first between-groups factor and used instructions (structured or free) as the second between-groups factor. Time was a within-groups factor as participants were required to complete two tests that indicate their mood and mental health conditions. Stress ball was used as a comparative object to clay because of its well-known effect of reducing anxiety through squeezing. Group A created pinch pots with clay, Group B was given clay to manipulate it freely, Group C tossed stress balls in a structured manner, and Group D manipulated stress balls freely. The researchers hypothesized that Group A, the group that was presented with structured manipulation, would result in the greatest mood benefits. The two tests used in the study were the Profile of Mood States (POMS) and the State-Trait Anxiety Inventory (STAI). POMS is a psychological rating scale that measures global negative mood, developed by McNair, Droppleman, and Lorr in 1971. On the other hand, STAI, developed by Spielberger in 1983, specifically measures trait and state anxiety.

Table 1. POMS Overall Negative Mood Scores at Baseline, Pre-Treatment, and Post-Treatment (Means and Standard Deviations)

\begin{tabular}{|lllclc|}
\hline Group & $\boldsymbol{N}$ & Baseline & Pre & Post & Pre-Post \\
\hline Clay Structured & 27 & $39.6(12.6)$ & $50.3(14.5)$ & $33.8(7.7)$ & $16.5(12.0)$ \\
Clay Free & 24 & $39.2(10.4)$ & $50.0(13.5)$ & $37.3(11.7)$ & $12.7(9.6)$ \\
Clay Total & 51 & $39.4(11.5)$ & $50.1(13.9)$ & $35.4(9.8)$ & $14.7(11.0)$ \\
Stress Ball Structured & 27 & $41.1(12.5)$ & $50.0(12.9)$ & $41.4(12.4)$ & $8.6(7.9)$ \\
Stress Ball Free & 24 & $38.4(7.5)$ & $50.8(10.3)$ & $38.5(10.0)$ & $12.3(10.2)$ \\
Stress Ball Total & 51 & $39.9(10.4)$ & $50.4(11.6)$ & $40.1(11.3)$ & $10.3(9.2)$ \\
\hline Note. For the Pre-Post scores, positive values indicate improved mood (reductions in state anxiety). \\
\hline
\end{tabular}


Table 2. STAI-S Scores at Baseline, Pre-Treatment, and Post-Treatment (Means and Standard Deviations)

\begin{tabular}{|lllccc|}
\hline Group & $\boldsymbol{N}$ & Baseline & Pre & Post & Pre-Post \\
\hline Clay Structured & 27 & $39.6(12.6)$ & $50.3(14.5)$ & $33.8(7.7)$ & $16.5(12.0)$ \\
Clay Free & 24 & $39.2(10.4)$ & $50.0(13.5)$ & $37.3(11.7)$ & $12.7(9.6)$ \\
Clay Total & 51 & $39.4(11.5)$ & $50.1(13.9)$ & $35.4(9.8)$ & $14.7(11.0)$ \\
Stress Ball Structured & 27 & $41.1(12.5)$ & $50.0(12.9)$ & $41.4(12.4)$ & $8.6(7.9)$ \\
Stress Ball Free & 24 & $38.4(7.5)$ & $50.8(10.3)$ & $38.5(10.0)$ & $12.3(10.2)$ \\
Stress Ball Total & 51 & $39.9(10.4)$ & $50.4(11.6)$ & $40.1(11.3)$ & $10.3(9.2)$ \\
\hline Note. For the Pre-Post scores, positive values indicate improved mood (reductions in state anxiety). & \\
\hline
\end{tabular}

Participants were given both the POMS and STAI before the experiment started. The scores are reflected in the "Baseline" column in the chart above in Tables 1 and 2. After the first assessment, participants then watched a 12minute video about traumatic new stories that occurred in the past 10 years. Participants were asked to reflect upon themselves after the video, creating a similar level of negative mood among the participants. They then once again filled out the tests, and these are the "Pre" scores. The study then began, and each group was given the assigned objects and instructions. The activities lasted for five minutes, and once the activities were over, participants again filled out the POMS and STAI forms. The final scores are reflected in the "Post" column.

In both Tables 1 and 2, the "Clay Total" and "Stress Ball Total" rows show the magnitude of the effect. When "Pre" and "Post" scores are compared in the POMS test, as seen in Table 1, there's a 45-point difference for the clay work group, whereas the stress ball group only had approximately 29-point difference. Similarly, for the STAI-S test shown in Table 2, the clay work group had a 15-point difference, and the stress ball group had a 10-point difference. In both tests, there's nearly a 50\% greater improvement in mood for clay intervention conditions. Also, results in both tables reveal that the advantages of clay over stress balls are more noticeable when in a structured condition instead of a free condition. The results of the study support the claim that clay's unique elements and properties for emotional regulation are more than its ability to be manipulated. The trend towards a larger effect in structured clay work in both tests shows that art therapy is most effective when individuals are given a structured instruction and specific goals.

This study also carries limitations as it did not involve facilitation of a therapist and participants were not individuals diagnosed with mental disorders. The short-term session design of the study is also a limitation to the study since most art therapy interventions last longer and more frequently.

Among art therapy, various studies on the effect of using clay have been actively conducted, and the effect of relieving anxiety and depression has been reported in general. In particular, research to quantify the effect through group studies has been conducted.

In Effect on scores of depression and anxiety in psychiatric patients after clay work in a day hospital (de Morais, A. H et al., 2014), researchers studied the effect of clay therapy by comparing the two groups of patients: one group that received therapy and the other that did not receive therapy. Participants experiencing depression, bipolar disorder, anxiety disorder, and other mental disorders while being over 18 years old, not under influence of drugs, and not experiencing crisis were included in the study. There was a total of 24 participants. 12 were in the control group (no clay work) and the other 12 were in the clay work group (divided into 2 groups, six weeks, 8 sessions for 3 hours each). Participants in the clay work group reported feelings and described the meaning of their clay sculptures every session. Depression was measured using the Beck Depression Inventory, and anxiety was measured with the Spielberger's State-Trait Anxiety Inventory. Then, Mann-Whitney test was used to study the effects of clay therapy by comparing the two group's scores, using the significance threshold of 0.05 . 
Table 3. Depression and anxiety scores in the control and clay work groups.

\begin{tabular}{|c|c|c|c|c|}
\hline \multirow[t]{2}{*}{ Patients } & \multicolumn{2}{|c|}{ Depression } & \multicolumn{2}{|l|}{ Anxiety } \\
\hline & Control & Clay work & Control & Clay work \\
\hline 1 & 35 & 15 & 69 & 35 \\
\hline 2 & 11 & 7 & 45 & 34 \\
\hline 3 & 26 & 15 & 45 & 51 \\
\hline 4 & 30 & 19 & 62 & 31 \\
\hline 5 & 13 & 13 & 40 & 35 \\
\hline 6 & 36 & 7 & 61 & 31 \\
\hline 7 & 33 & 14 & 69 & 56 \\
\hline 8 & 31 & 14 & 64 & 47 \\
\hline 9 & 22 & 15 & 58 & 66 \\
\hline 10 & 10 & 12 & 43 & 58 \\
\hline 11 & 13 & 12 & 31 & 48 \\
\hline 12 & 17 & 13 & 38 & 47 \\
\hline Mean & 23.1 & 13 & 52.08 & 44.9 \\
\hline Standard deviation & 9.9 & 3.4 & 13.1 & 11.7 \\
\hline Standard error & 2.9 & 0.97 & 3.79 & 3.37 \\
\hline$n$ & 12 & 12 & 12 & 12 \\
\hline
\end{tabular}

Figure 1. Comparison of depression and anxiety scores between the clay work and control groups.

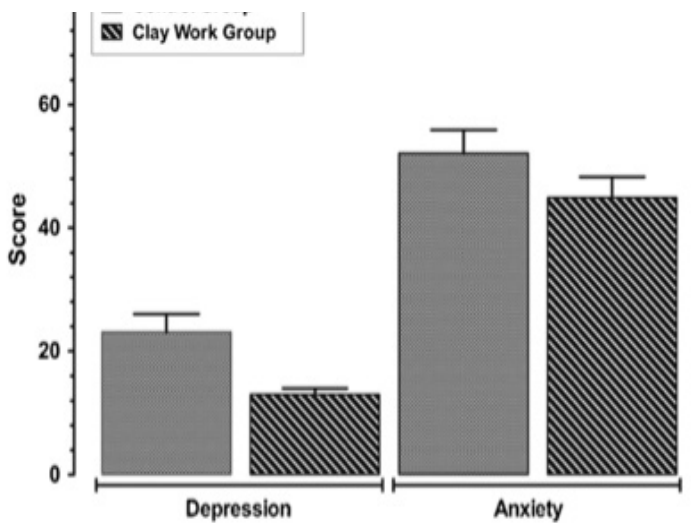

As seen in Table 3 and Figure 1, the clay work group's average score was $13 \pm 0.97$, indicating mild depression, while the control's group's scores have an average of $23.1 \pm 2.9$, indicating moderate depression. Anxiety measurements also followed the trend, as the clay work group has an average score of $44.9 \pm 3.37$, while the control group's average was $52.08 \pm 3.79$. The study suggests that there were improvements in both depression and anxiety, proving the effects of clay therapy on mental disorder patients. However, there were also limitations to this study, such as the small sample size of individuals studied. The improvement in scores can be accounted for by the soothing nature of clay work. Studies claim that clay work assists patients to release repressed emotions, such as feelings of helplessness or depression, and this release ultimately leads to physical and psychological well-being (Greenberg \& Stone, 1992; Jang \& Chol, 2012). With the ability to physical touch and manipulate, patients also possess a sense of control over their feelings through their hands, and the therapy allows communication of conscious and unconscious content and feelings (Benau, 2009; Bozza, 2001; Henley,2002; Jang \& Chol, 2012; Orbach \& Galukin, 1997; Ramos, 2005, Snir \& Regev, 2013).

\section{Conclusion}

According to estimates provided by the Center for Disease Control and Prevention's Autism and Developmental Disabilities Monitoring Network (2016), one in 54 children are diagnosed with ASD by age 8 each year (CDC, 2020). Autism Spectrum Disorder still remains a behaviorally defined disorder with no known biological markers to aid with diagnosis and subgroup categorization at this point (Anagnostou E. \& Taylor M. J., 2011). In order to find the cause of the disorder, deeper research is necessary. Recent neurobiological studies claim that autism spectrum disorders are characterized by atypical brain connectivity, in which the cortical-cortical connectivity decreases and connectivity between subcortical regions and sensory areas increases (Anagnostou E. \& Taylor M. J., 2011). Due to the findings of the impact ASD has on brain connectivity, we need to understand ASD within the context of developmental neurobiology.

ASD affects many people, and many studies are being conducted using technologies such as neuroimaging to determine the cause. However, in order to improve each individual's condition, art therapy still has to play an important role.

Past research papers have suggested that sympathy and verbal and non-verbal communication with patients in the treatment of depression disorder can be enhanced through clay therapy that provides tactile and visual stimulation. The advantages of clay art therapy mentioned in the papers have been considered as important factors for 
ASD treatment. In particular, clay improves communication with patients through emotional interaction and nonverbal communication and provides a soothing effect through touch and manipulation. By being able to change the shape of clay with their own abilities, patients are expected to achieve a sense of control over their feelings, which is expected to be of great help in ASD treatment. Clay therapy is proven to benefit patients with mental disorders that individuals with ASD also suffer. Although clay is a helpful method for people with ASD, since clay is sticky and has a bad feel that people may dislike, finding other materials that have improved these things can ameliorate these shortcomings, making it more appealing to more ASD patients. expected to be applicable. To broaden the scope of the effectiveness of art therapy, it is necessary to verify the effect by applying a material that promotes tactile sense, such as clay, to a large scale of individuals with autism spectrum disorder. Because the previous studies were mostly done with small sample size, in order to achieve a better understanding of the overall impact of clay therapy, larger sample size is necessary. The potential of art therapy usage for individuals with autism spectrum disorder is limitless, and it will pave the way for the children to improve their conditions by using both their physical senses and creativity.

\section{Acknowledgements}

I would like to express my gratitude to my advisor, Paul Shim, who guided me throughout the research process. I also wish to show my appreciation to the staff members at Organization of Special Needs Families who offered me deep insight about the topic and supported me.

\section{References}

Anagnostou, E., \& Taylor, M. J. (2011). Review of neuroimaging in autism spectrum disorders: what have we learned and where we go from here. Molecular Autism, 2(1), 4. https://doi.org/10.1186/2040-2392-2-4

Benau, K. S. (2009). Contrast, symbol formation and creative transformation in art and life. Psychoanalytic Review, 96(1), 83-112.

Bozza, M. G. (2001). Clay: Mirror of self-expression: A method for the manifestation of the unconscious. Curitiba: Editora do Autor (in Portuguese).

Centers for Disease Control and Prevention. (2020, September 25). Data \& Statistics on Autism Spectrum Disorder. Centers for Disease Control and Prevention. https://www.cdc.gov/ncbddd/autism/data.html.

D'Amico, M., \& Lalonde, C. (2017). The Effectiveness of Art Therapy for Teaching Social Skills to Children With Autism Spectrum Disorder. Art Therapy, 34(4), 176-182. https://doi.org/10.1080/07421656.2017.1384678

de Morais, A. H., Dalécio, M. A., Vizmann, S., Bueno, V. L., Roecker, S., Salvagioni, D. A., \& Eler, G. J. (2014). Effect on scores of depression and anxiety in psychiatric patients after clay work in a day hospital. The Arts in Psychotherapy, 41(2), 205-210. https://doi.org/10.1016/j.aip.2014.02.002

Frith, C., \& Law, J. (1995). Cognitive and Physiological Processes Underlying Drawing Skills. Leonardo, 28(3), 203. https://doi.org/10.2307/1576075

Greengerg, M. A., \& Stone, A. A. (1992). Emotional disclosure about trauma and its relation to health: Effects of previous disclosure and trauma severity. Journal of Personality and Social Psychology, 63(1), 75-84.

Groth-Marnat, G. (1997). Handbook of psychological assessment. (3rd ed., pp. 499-533). New York: Wiley. Henley, D. (2002). Clayworks in art therapy: Plying a sacred circle. Philadelphia: Jessica Kingsley.

Huma Durrani (2020): Sensory-Based Relational Art Therapy Approach (S-BRATA): A Framework for Art Therapy With Children With ASD, Art Therapy, https://doi.org/10.1080/07421656.2020.1718054

Jang, H., \& Chol, S. (2012). Increasing ego-resilience using clay with low SES (Social Economic Status) adolescents in group art therapy. The Arts in Psychotherapy, 39, 245-250. 
Ka-Young Oh. (2011). A Case study on the Effect of Art Therapy Improvement of the sociality of an Autistic Child. Korean Journal of Culture and Arts Education Studies, 6(3), 123-144. https://doi.org/10.15815/kjcaes.2011.6.3.123

Kimport, E. R., \& Robbins, S. J. (2012). Efficacy of Creative Clay Work for Reducing Negative Mood: A Randomized Controlled Trial. Art Therapy, 29(2), 74-79. https://doi.org/10.1080/07421656.2012.680048

Lim, J. H., Lee, B. J., \& Shin, J. H. (2015). The Effects of Art Therapy on Self Expression of Adolescents with Autistic Disorder. JOURNAL OF SPECIAL EDUCATION \& REHABILITATION SCIENCE, 54(4), 339. https://doi.org/10.15870/jsers.2015.12.54.4.339

Malchiodi, C. A. (Ed.). (2012). Handbook of art therapy (2nd ed.). The Guilford Press.

McNair, D. M., Lorr, M., \& Droppleman, L. F. (1971). Manual of the Profile of Mood States. San Diego, CA: Educational and Industrial Testing Service.

Moghaddam K, Zadeh Mohammadi A, Sharifi Daramadi P, Afrooz G. Effect of the Family-based Art Therapy Program on the Social Interactions, Verbal Skills and Stereotypic Behaviors of Children with Autism Spectrum Disorders (ASD). Iran J Public Health. 2016 Jun;45(6):830-2. PMID: 27648433; PMCID: PMC5026845.

Motta, R. W., Little, S. G., \& Tobin, M. I. (1993). The use and abuse of human figure drawings. School Psychology Quarterly, 8(3), 162-169. https://doi.org/10.1037/h0088273

Orbach, N., \& Galukin, L. (1997). The spirit of materials: Art therapy - Procedures and experiences. Kiryat-Bialik: Ach.

Ramachandran, V. S., \& Blakeslee, S. (1999). Phantoms in the Brain: Probing the Mysteries of the Human Mind. Mondadori.

Ramos, T. C. (2005). Art therapy as support for human developmental disorders (Monograph in art therapy). Rio de Janeiro: Universidade Cândido Mendes (in Portuguese).

Rankin, A. (1994). Tree Drawings and Trauma Indicators: A Comparison of past Research with Current Findings from the Diagnostic Drawing Series. Art Therapy, 11(2), 127-130. https://doi.org/10.1080/07421656.1994.10759064

Snir, A., \& Regev, D. (2013). A dialog with five art materials: Creators share their art making experiences. The Arts in Psychotherapy, 40, 94-100.

Spielberger, C. D. (1983). Manual for the State-Trait Anxiety Inventory (Form Y). Palo Alto, CA: Counseling Psychologists. 